\title{
Differences of novice to black belt Aikido practitioners in mindfulness: A longitudinal study
}

\author{
John Lothes · Robert Hakan · Kirk Mochrie
}

\begin{abstract}
The martial art aikido may be useful in the development of mindfulness (Lothes, Hakan, \& Kassab, 2013) and is often philosophically referred to as a meditation in motion, because of the heightened awareness that is ascribed to the training (Dobson \& Miller, 1978; Saotome, 1986, 1989). Fuller (1988) argued that martial arts training, especially aikido, has the potential for positive psychological effects such as increased self-control, increased awareness of self and of others and overall increased health and wellbeing. Davidson (2010) argues more longitudinal research needs to be done to examine the changes of mindfulness over time. The current study was a longitudinal assessment of mindfulness in five aikido students of the University of North Carolina Wilmington Aikido Club from their starting through to their obtaining their black belts (a minimum of five years of training). The KIMS/MAAS was administered to these participants at nine intervals over the time course of their advancement in aikido. Results showed a significant increase of selfreported mindfulness from the beginning of training to the achievement of black belt status. Since the length of time from starting to achieve the black belt is approximately five years minimum, this unique longitudinal study affords us the opportunity to see what long-term effects aikido training has on individual's levels of mindfulness.
\end{abstract}

Keywords: aikido, mindfulness, wellbeing, positive psychology

\section{Introduction}

Aikido is a specific type of martial arts training that involves basic body movements practiced individually (Aiki taiso), and with a partner (Tai Sabaki) (Lothes, Hakan, Kassab, 2013). "Aiki taiso" involves an awareness component through breathing and exercises in balance, whereas "Tai Sabaki" allows the practitioner to learn cooperation and timing in movement. Individuals are also taught basic techniques (Kihon waza) to effectively throw, pin, and blend or adapt with other people (Lothes, et al., 2013).

Individuals who practice aikido tend to increase overall awareness, awareness of body position, awareness of others around the aikido practitioner, awareness of their own emotional states, and how other people's emotions may affect the aikido practitioner's emotional states (Lothes, et al., 2013; Westbrook \& Ratti, 1970; Shifflett, 1999). Consequently, aikido has been described as meditation in motion (Dobson \& Miller, 1978; Saotome, 1986, 1989) and has been argued to have the potential for positive psychological effects (Fuller, 1988). It has been suggested there is a link between aikido practice and mindfulness (Lothes, et al., 2013).

Mindfulness has been considered a multifaceted construct which incorporates non-reactive observation and description, and acting with awareness without judgment (Baer, Smith, Hopkins, Kreitemeyer, \& Toney, 2006). Further, aikido is likely to be related to mindfulness in the following ways: mindfulness of aikido technique, breathing, balance, center of gravity, and

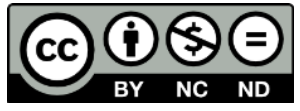

Copyright belongs to the author(s) www.internationaljournalofwellbeing.org 
connection to others (Shioda, 1968, 1991; Ueshiba, 1984). Although it seems there may be an unambiguous relationship between mindfulness and aikido little literature addresses this relationship.

We have recently begun to address this issue (Lothes, et al., 2013). Results from a betweengroup assessment showed aikido practitioners scored significantly higher on mindfulness measures than control participants with no martial arts training. Also, black belts (Dan ranks) scored significantly higher than non-black belts (kyu ranks) on measures of mindfulness. Lothes, et. al. (2013) also examined longitudinal (over 6 months) data among aikido students and found that mindfulness scores increased among beginners (i.e. all those in kyu ranks).

Davidson (2010) argues longitudinal studies on mindfulness should be encouraged: "Unless we had measures at different points along the continuum of training, we could not disentangle training effects from the study of those individuals who are likely to persist in such training" (p. 9). The present study attempts to extend our previous work by examining differences in mindfulness scores from novice to black belt aikido practitioners over a five-year period as compared to the six months that was assessed in the previous Lothes, et al., (2013) study. Since the length of time from starting to black belt is approximately five years minimum (see Table 1), the present longitudinal study affords us the unique opportunity to examine the long-term effects of aikido training on mindfulness.

\section{Method}

\subsection{Participants}

Beginning students (no prior martial arts experience) of the University of North Carolina Wilmington Aikido Club were recruited for the study. Five ( 1 woman, 4 men) people volunteered as aikido participants in the study. Four Caucasians and one African American participated in the study. The average age at start was 20.4 years old. The average age at Black Belt was 25.4.

\subsection{Measures}

The Kentucky Inventory of Mindfulness Skills (KIMS) and Mindful Attention Awareness Scale (MAAS) were used to assess mindfulness for this longitudinal study. The Kentucky Inventory of Mindfulness Skills and the Mindfulness Attention Awareness Scale are both empirically validated measurements of mindfulness.

The Kentucky Inventory of Mindfulness Skills (KIMS; Baer, Smith, \& Allen, 2004) measures mindfulness with 39 items using a 5-point response scale. The KIMS includes statements about observing, describing, acting with awareness, and accepting without judgment (Baer, Smith \& Allen, 2004). Total scores may range from 39 to 195, with higher scores indicating greater levels of self-reported mindfulness. Internal consistency reliability has been demonstrated to be high (Cronbach's alpha of .87; Baer, Smith \& Allen, 2004).

The Mindfulness Attention Awareness Scale (MAAS; Brown \& Ryan, 2003) measures consciousness associated with enhanced self-awareness. Participants respond to 15 statements on a 6-point scale. Total scores may range from 15 to 90, with higher scores indicating greater self-awareness. Internal consistency reliability has been determined to be high (Cronbach's alpha of .87; Brown \& Ryan, 2003). Internal consistency reliability for both the KIMS and the MMAS in our study was good with Cronbach's alpha of .91 for KIMS and .91 for MAAS. 


\subsection{Procedures and design}

Aikido classes were offered four nights a week, with each training session lasting two hours. There was no randomization of assignment in this study since all students were self-selected. Participants of the UNCW Aikido Club paid dues of \$25 per month to belong to the club and train. Participants were asked if they would be willing to volunteer for a study examining the effects of aikido training on mindfulness after the third class that they attended. After individuals agreed to participate they were given informed consents to sign and received a copy for their records. To insure that all information remained confidential participants were asked to use code names and surveys were kept in the principal investigator's office.

Initially mindfulness surveys were given to the participants to take home after they joined the club. Then participants were assessed for mindfulness ratings using the KIMS and MAAS upon each successful completion of their belt test. This was a total of nine assessments from start to black belt (see Table 1 below).

Table 1. Ranks, approximate timing of rank achievement by standards, and estimated time of experience

\begin{tabular}{lll}
\hline Rank & Approximate timing of training & $\begin{array}{l}\text { Estimated Experience years / } \\
\text { months }\end{array}$ \\
\hline $7^{\text {th }} \mathrm{kyu}$ & 2 months training after starting & 3 months \\
$6^{\text {th }} \mathrm{kyu}$ & 3 months training after $7^{\text {th }} \mathrm{kyu}$ & 6 months \\
$5^{\text {th }} \mathrm{kyu}$ & 4 months training after $6^{\text {th }} \mathrm{kyu}$ & 11 months \\
$4^{\text {th }} \mathrm{kyu}$ & 5 months training after $5^{\text {th }} \mathrm{kyu}$ & 1 yr 4 months (16 months) \\
$3^{\text {rd }} \mathrm{kyu}$ & 6 months training after $4^{\text {th }} \mathrm{kyu}$ & 2 yrs (24 months) \\
$2^{\text {nd }} \mathrm{kyu}$ & 8 months training after $3^{\text {rd }} \mathrm{kyu}$ & 2 yrs 8 months (32 months) \\
$1^{\text {st }} \mathrm{kyu}$ & 10 months training after $2^{\text {nd }} \mathrm{kyu}$ & 3 yrs 8 months $(44$ months $)$ \\
Shodan & $1^{\text {st }}$ degree black belt, 12 months after 1 st kyu & 4 yrs 8 months (56 months) \\
Nidan & $2^{\text {nd }}$ degree black belt, min. 24 months after & 7 yrs (84 months) \\
& Shodan & \\
\hline
\end{tabular}

As aikido students moved through their training, they were required to display a certain proficiency in understanding of technique and pass a belt test administered by one or more instructing black belts before being approved to move onto the next belt rank. Measurements of mindfulness were conducted after a participant successfully completed each belt test according to the Aikido World Alliance testing standards. In addition to passing their belt tests each participant was required to undertake a minimum time of training between each test as shown in Table 1. Though these are minimum time requirements before an individual is allowed to be tested for the next belt, it is not uncommon for someone to take 5 years or longer to achieve a black belt in aikido.

\section{Results}

One-way repeated measures ANOVAs were used to assess the effect of aikido training on mindfulness scores on the KIMS and the MAAS from start to black belt (Shodan). As illustrated by Figures 1 and 2 below, there was a significant effect of aikido experience on the KIMS measures of mindfulness between start $(\mathrm{M}=130.40, \mathrm{SD}=14.064)$ and Shodan (black belt) (M $=158.80, \mathrm{SD}=16.41)\left(\right.$ Wilks Lambda $\left.=19.695, F_{1,4}=2.462 p<.0334, \eta^{2}=.821\right)$ and also for the MAAS 
between start $(M=60.60, S D=10.74)$ and Shodan (black belt) $(M=70.80, S D=13.31)($ Wilks Lambda $\left.=18.201, F_{1,3}=2.275, p<.05, \eta^{2}=.783\right)$.

Figure 1: Mean scores for KIMS Start and KIMS Shodan (Black Belt) scores

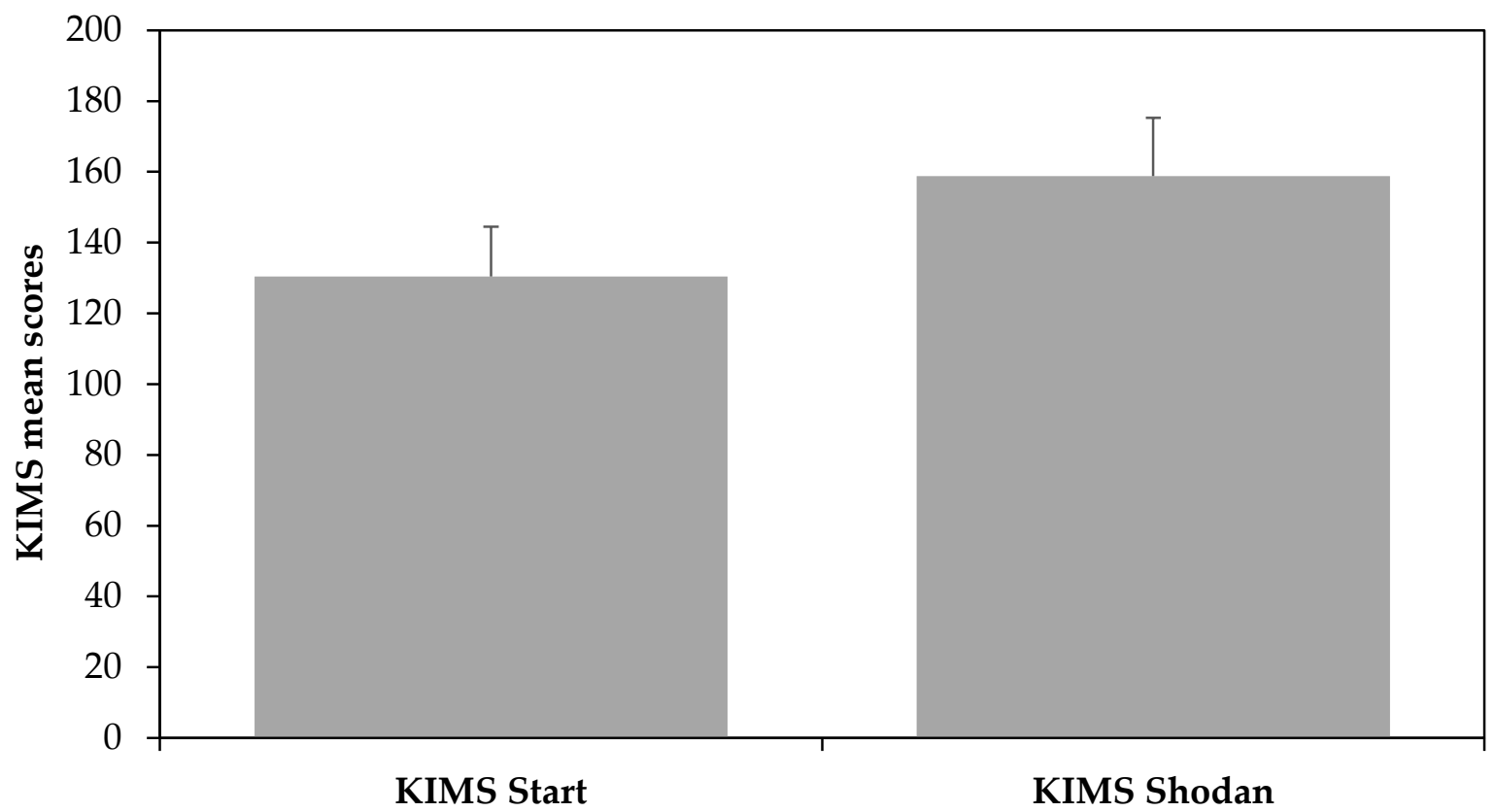

Figure 2: Mean scores for MAAS Start and MAAS Shodan (Black Belt) scores

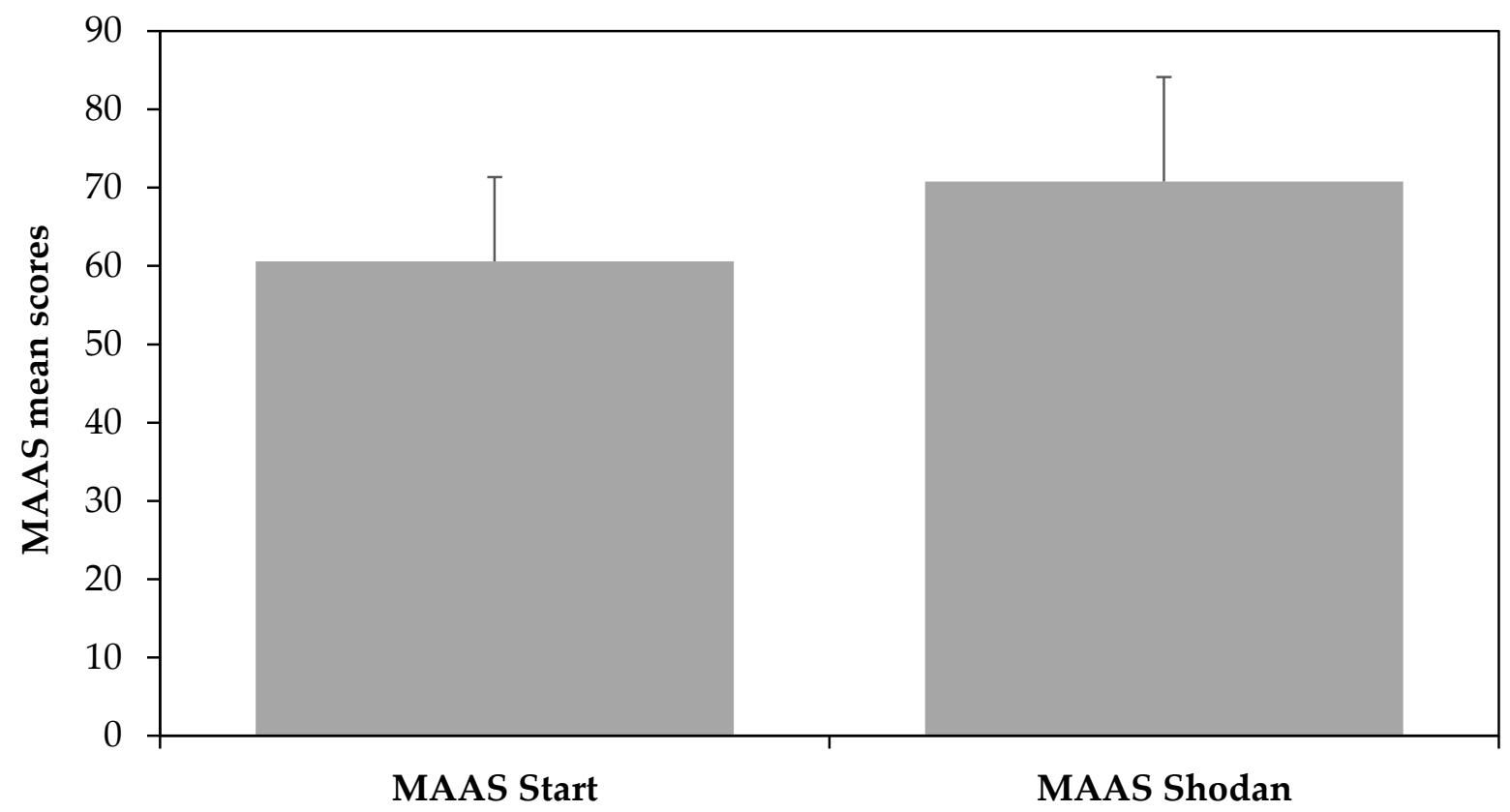

Table 2 below presents post-hoc assessments of KIMS scores, which showed that the significant repeated measures outcome was accounted for primarily by differences between Start and $3^{\text {rd }}$ kyu $(\mathrm{p}<.01)$, start and Shodan $(\mathrm{p}<.02)$, and $7^{\text {th }} \mathrm{kyu}$ and Shodan $(\mathrm{p}<.04)$. These findings are illustrated in Figure 3 below. 
Table 2: Means table for KIMS scores after each successful belt test completion

\begin{tabular}{|c|c|c|c|}
\hline Rank & Mean & Standard Deviation & Standard Error \\
\hline KIMS Start & 130.40 & 14.06 & 6.29 \\
\hline KIMS $7^{\text {th }} \mathrm{kyu}$ & 127.20 & 17.20 & 7.69 \\
\hline KIMS $6^{\text {th }} \mathrm{kyu}$ & 136.20 & 16.35 & 7.31 \\
\hline KIMS $5^{\text {th }} \mathrm{kyu}$ & 138.40 & 12.52 & 5.60 \\
\hline KIMS $4^{\text {th }} \mathrm{kyu}$ & 140.20 & 16.68 & 7.46 \\
\hline KIMS $3^{\text {rd }} \mathrm{kyu}$ & $145.80^{*}$ & 14.04 & 6.28 \\
\hline KIMS $2^{\text {nd }} \mathrm{kyu}$ & 139.80 & 19.50 & 8.72 \\
\hline KIMS $1^{\text {st }} \mathrm{kyu}$ & 142.20 & 17.66 & 7.90 \\
\hline KIMS Shodan & $158.80^{* *}$ & 16.41 & 7.34 \\
\hline
\end{tabular}

${ }^{*}$ Indicates significant difference from start

${ }^{* *}$ Indicates significant difference from $7^{\text {th }} \mathrm{kyu}$

Figure 3: Mean scores combined for KIMS at each successful belt test completion from start to Shodan (Black Belt)

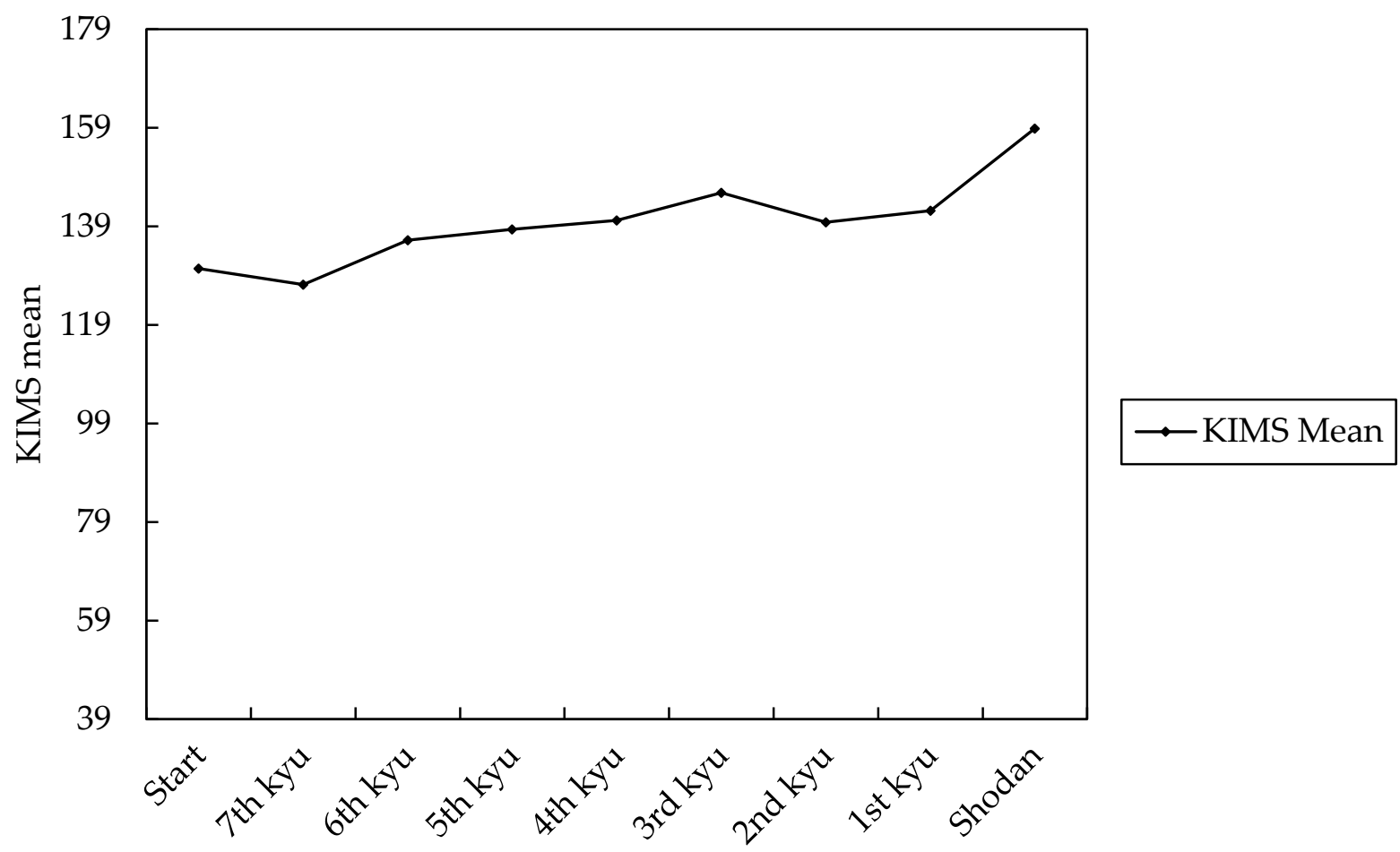

Table 3 below presents post-hoc assessments of MAAS scores, which showed that the significant repeated measures outcome was accounted for primarily by differences between start and 1st kyu $(\mathrm{p}<.02)$, 7th kyu and Shodan $(\mathrm{p}<.04)$, and 5th kyu and Shodan $(\mathrm{p}<.007)$. These findings are illustrated in Figure 4 below. 
Table 3: Means table for MAAS after each successful belt test completion

\begin{tabular}{|c|c|c|c|}
\hline Rank & Mean & Standard Deviation & Standard Error \\
\hline MAAS Start & 60.60 & 10.74 & 4.08 \\
\hline MAAS $7^{\text {th }} \mathrm{kyu}$ & 57.60 & 15.01 & 6.71 \\
\hline MAAS $6^{\text {th }} \mathrm{kyu}$ & 68.40 & 2.61 & 1.17 \\
\hline MAAS $5^{\text {th }} \mathrm{kyu}$ & 62.20 & 10.92 & 4.88 \\
\hline MAAS $4^{\text {th }} \mathrm{kyu}$ & 66.00 & 9.62 & 4.30 \\
\hline MAAS $3^{\text {rd }} \mathrm{kyu}$ & 73.80 & 5.76 & 2.58 \\
\hline MAAS $2^{\text {nd }} \mathrm{kyu}$ & 66.80 & 12.07 & 5.40 \\
\hline MAAS $1^{\text {st }} \mathrm{kyu}$ & $67.60^{*}$ & 13.24 & 5.92 \\
\hline MAAS Shodan & $70.80^{* *}$ & 13.31 & 5.95 \\
\hline
\end{tabular}

*Significantly different from start

**Significantly from start and from $7^{\text {th }} \mathrm{kyu}$

Figure 4: Mean scores combined for MAAS at each successful belt test completion from start to Shodan (Black Belt)

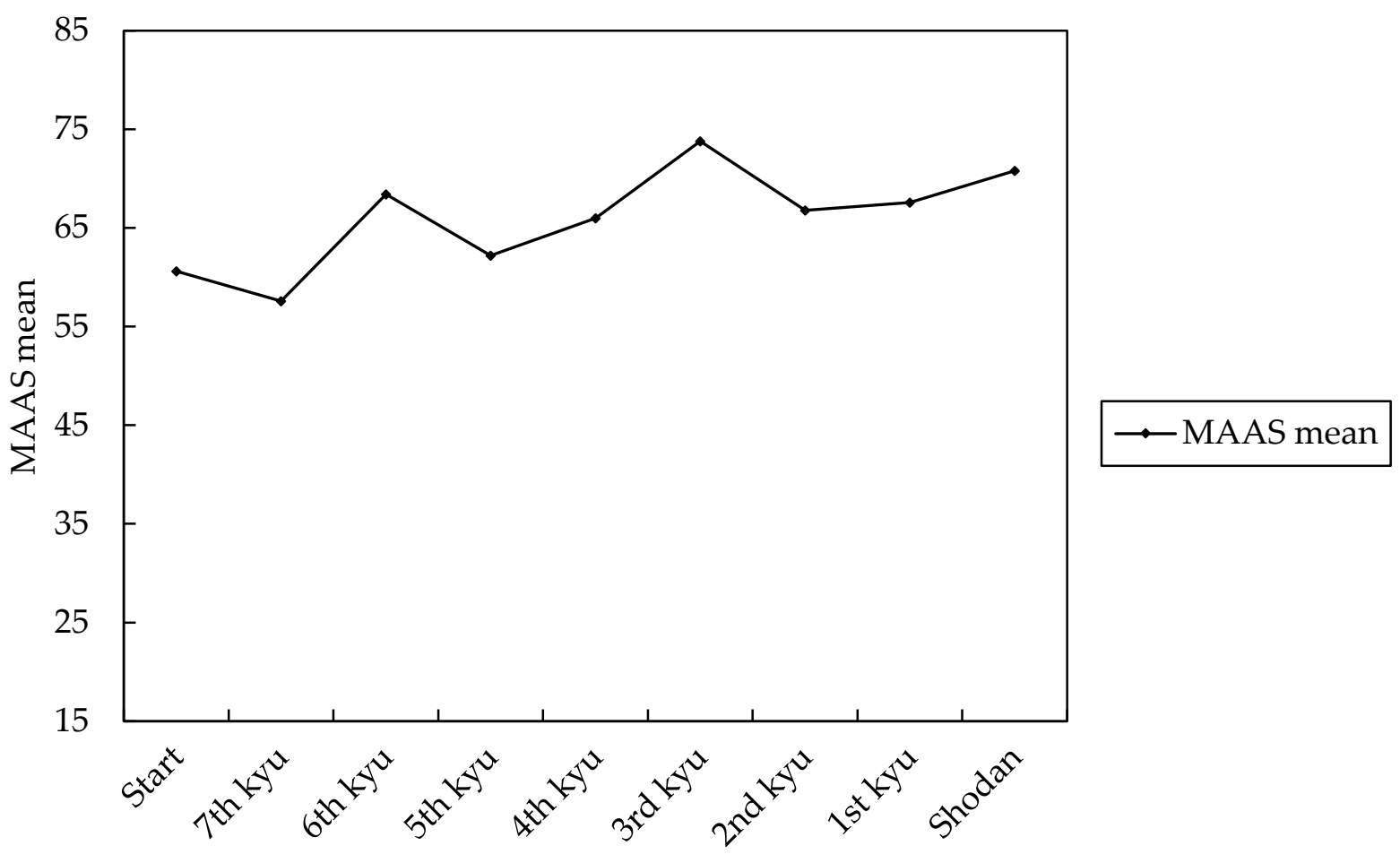

\section{Discussion}

The results of this five-year longitudinal study suggest that Aikido training may significantly increase ones' level of mindfulness. Benefits of increased mindfulness may include better concentration, enhanced awareness, improved immune system functioning and decreases in stress-related physical symptoms (Shapiro, Carlson, Astin, \& Freedman, 2006).

The results of this study support Lothes, et al. (2013), who reported that six months of aikido training increased mindfulness in beginners and suggested that continued long-term participation in aikido training may lead to increased levels of mindfulness. Participants were asked if they had started any meditative or mindfulness practices while doing aikido and all of them responded that they had not started any mindfulness practices since starting training. 
Moreover, KIMS and MAAS scores at the beginning of this study were compared to beginning scores of the Lothes, et al. (2013) study and no significant differences were observed. This diminishes the concern that individuals who carry on to Shodan levels of Aikido are initially different in mindfulness.

Although significant changes in KIMS and MAAS scores occurred over the course of this study, there was noticeable fluctuation in scores across points of measurement. The KIMS and MAAS were designed using language and terminology that is commonly taught to individuals who engage in a meditative practice. Aikido instruction does not provide specific meditative instruction or nomenclature, rather mindfulness is learned experientially (Kolb, 1984). These factors may explain some of the fluctuation in self-reported mindfulness scores. On the other hand, the progressive yet fluctuating scores across points of measure may be indicative of an interesting aspect of the development of mindfulness. It is logical that as one becomes initially more mindful greater attention is given to one's lapses of mindfulness; hence periodically lower scores may result as one is moving toward greater mindfulness.

We predicted a significant difference in mindfulness scores from start to black belt. We did not expect and we did not find the degree of difference that has been reported with mindfulness or meditation training populations (Tanner, et al., 2009). Comparisons across studies may be problematic in a number of ways (Quickel, Johnson, \& David, 2014). Self-reported studies of mindfulness on individuals participating in meditation and/or mindfulness programs may be more inclined to report higher levels of mindfulness due to demand characteristics (Vartanian \& Powlishta, 2001), where individuals are reporting higher levels of mindfulness because they are supposed to be more mindful. Rosnow (2002) describes demand characteristics as any "taskorienting cues" that may produce a subject bias. The individuals in this study were not directed towards any specific mindfulness language or descriptors; they were instructed on matters of present moment awareness through their aikido training.

To date we are not aware of any five-year mindfulness meditation studies. Our results are consistent with studies that have compared and examined the process of meditation on mindfulness. Tanner, et al. (2009) examined the effects of Transcendental Meditation (TM) on mindfulness scores using the KIMS. At the start, Tanner et al.'s Wait List group $(M=128.03)$ and TM start group $(M=127.48)$ were not significantly different. After three months, the Wait List group did not show any increases in mindfulness scores $(M=128.42)$, while their TM group did show significant increases in self-reported mindfulness scores $(M=135.08)$. These results are consistent with Lothes, et al. (2013) and our current study found that aikido training develops a cultivation of mindfulness. In addition, Brown and Ryan's (2003) results suggested that years of meditation practice were related to higher MAAS scores. These results with MAAS scores are also represented in our study. Vinchurkar, Singh, and Visweswaraiah (2014) found a positive relationship between cyclic meditation, which is also considered a meditation in action like aikido, with higher levels of self-reported mindfulness on the MAAS.

One potential problem Davidson (2010) points out is that, "While participants can be expected to provide reasonably accurate reports of the times of their formal practice periods, it is not clear the extent to which participants can accurately provide self-reports on the quality of practice" (p.9). The present study does provide both accurate reports of formal practice periods and quality of practice, since these practitioners had not only to meet their minimum training time requirements before moving onto the next belt rank, but also had to successfully complete a set of prescribed aikido techniques in front of a panel of Black Belt Aikido instructors before being awarded their next rank. Therefore, this long-term longitudinal study informs mindfulness research literature as suggested by Davidson. 
This longitudinal study tracked a small number of students across five years of aikido training. It is acknowledged that the small sample size is a limitation and that the design of the study cannot support a causal conclusion. However, the uniqueness of this study and the difficulty in tracking students over a multi-year period must be given merit and invites further consideration about causal linkage. Suggested research includes tracking and examining mindfulness against matched control groups. It may also be of interest to assess mindfulness levels of individuals who drop out of training. Other factors to be considered in future research might include examining the mechanisms through which aikido might increase levels of mindfulness (Shapiro, Carlson, Astin, \& Freedman, 2006).

\section{Acknowledgments}

The authors would like to thank Andrew Sato Sensei of the Aikido World Alliance, Richard Price Sensei of Kure Beach Aikido and Dr. Catherine Ibsen for their help and insights on aikido, mindfulness and data collection.

\section{Authors}

John Lothes

University of North Carolina Wilmington

lothesj@uncw.edu

Robert Hakan, Phd

University of North Carolina Wilmington

Kirk Mochrie, MA

University of North Carolina Wilmington

\section{Publishing Timeline}

Received 4 February 2015

Accepted 7 May 2015

Published 30 July 2015

\section{References}

Baer, R., Smith, G., \& Allen, K. (2004). Assessment of mindfulness by self-report. Assessment, 11, 191-206. http://dx.doi.org/10.1177/1073191104268029

Baer, R., Smith, G., Hopkins, J., Kreitemeyer, J., \& Toney, L. (2006). Using self-report assessment methods to explore facets of mindfulness. Assessment, 13, 27-45. http://dx.doi.org/10.1177/1073191105283504

Brown, K., \& Ryan, R. (2003). The benefits of being present: Mindfulness and its role in psychological well-being. Journal of Personality and Social Psychology, 84, 822-848. http://dx.doi.org/10.1037/00223514.84.4.822

Davidson R.J. (2010). Empirical explorations of mindfulness: Conceptual and methodological conundrums. Emotion, 10(1), 8-11. http://dx.doi.org/10.1037/a0018480

Dobson, T., \& Miller, V. (1978). Aikido in everyday life: Giving in to get your way. Berkeley, CA: North Atlantic Books.

Fuller, J. R. (1988). Martial arts and psychological health. British Journal of Medical Psychology, 61, 317-328. http://dx.doi.org/10.1111/j.2044-8341.1988.tb02794.x

Kolb, D.A. (1984). Experiential learning: Experience as the source of learning and development (Vol. 1). Englewood Cliffs, NJ: Prentice-Hall.

Lothes, J., Hakan, R., \& Kassab, K. (2013). Aikido experience and its relation to mindfulness: A two-part study. Perceptual and Motor Skills, 116(1), 30-39. http://dx.doi.org/10.2466/22.23.PMS.116.1.30-39 
Quickel, E., Johnson, S., \& David, Z. (2014). Trait mindfulness and cognitive task performance:

Examining the attentional construct of mindfulness. SAGE Open, 4(4), 1-8.

http://dx.doi.org/10.1177/2158244014560557

Rosnow, R. L. (2002). The nature and role of demand characteristics in scientific inquiry. Prevention \& Treatment, 5(1), 37. http://dx.doi.org/10.1037/1522-3736.5.1.537c

Saotome, M. (1986). Aikido and the harmony of nature. Boston: Shambhala

Saotome, M. (1989). The principles of aikido. Boston: Shambhala

Shapiro, S., Carlson, L., Astin, J., \& Freedman, B. (2006). Mechanisms of Mindfulness. Journal of Clinical Psychology, 62(3), 373-386. http://dx.doi.org/10.1002/jclp.20237

Shifflett, C. (1999). Aikido: Exercises for teaching and training. Merrifield, Round Earth Pub.

Shioda, G. (1968). Dynamic Aikido. Tokyo: Kodansha International.

Shioda, G. (1991). Aikido Shugyo: Harmony in confrontation. Toronto: Shindokan International.

Tanner M. A., Travis, F., Gaylord-King, C., Haaga, D.A., Grosswalk, S., \& Schneider, R. H. (2009). The effects of the transcendental meditation program on mindfulness. Journal of Clinical Psychology, 65 (6), 574-89. http://dx.doi.org/10.1002/jclp.20544

Ueshiba, K. (1984). The spirit of aikido. Tokyo: Kodansha International.

Vartanian, L., \& Powlishta, K. K. (2001). Demand characteristics and self-report measures of imaginary audience sensitivity: Implications for interpreting age differences in adolescent egocentrism. The Journal of Genetic Psychology: Research and Theory on Human Development, 162(2), 187-200. http://dx.doi.org/10.1080/00221320109597960

Vinchurkar, S. A., Singh, D., \& Visweswaraiah, N. K. (2014). Self-reported measures of mindfulness in meditators and non-meditators: A cross-sectional study. International Journal of Yoga, 7(2), 142-146. http://dx.doi.org/10.4103/0973-6131.133898

Westbrook, A., \& Ratti, O. (1970). Aikido and the dynamic sphere: An illustrated Introduction. Boston: Turtle. 